\title{
Does attachment style predict quality of life in youth? A cross-sectional study in Iran
}

\author{
Fatemeh Darban, ${ }^{1}$ Enayatollah Safarzai, ${ }^{2}$ Edris Koohsari, ${ }^{3}$ Mehri Kordi ${ }^{4}$ \\ 'School of Nursing and Midwifery, Iranshahr University of Medical Sciences, Iranshahr; \\ ${ }^{2}$ Department of Nursing, Ali-Ebne-Abitaleb Hospital, Zahedan,University of Medical Sciences, \\ Zahedan; ${ }^{3}$ Medical Emergencies, Iranshahr University of Medical Sciences, Iranshahr; ${ }^{4}$ Nursing \\ office, Iranshahr University of Medical Sciences, Iranshahr, Iran
}

\begin{abstract}
The attachment can be considered as a specific behavioral pattern that is critical to healthy growth in most communities. Medical students are exposed to high levels of psychological stress while being equipped with lower levels of resilience. This study aims to determine the relationship between attachment style and the quality of life of medical students. In this cross-sectional correlational study, 150 students of Iranshahr University of Medical Sciences in 2018 were selected based on convenience sampling with consideration of inclusion criteria. Revised Adult
\end{abstract}

Correspondence: Mehri Kordi, Nursing Office, Iranshahr University of Medical Sciences, Iranshahr, Iran.

Tel.: +98 5437220480

E-mail: mehrikordi79@gmail.com

Key words: Attachment style, quality of life, youth.

Contributions: FD and MK designed the model and the computational framework and analyzed the data; ES and EK carried out the implementation; FD performed the calculations darban and MK wrote the manuscript with input from all authors; FD and MK conceived the study and were in charge of overall direction and planning.

Acknowledgments: We appreciate all the students who participated in this study.

Conflict of interest: The authors have no conflict of interest to declare.

Ethical approval and consent to participate: This study was conducted after being approved by the Ethics Committee of Iranshahr University of Medical Sciences (13-923).

Consent for publication: This study was approved by the Ethics Committee of Iranshahr University of Medical Sciences.

Availability of data and materials: All data and materials are available within the text.

Received for publication: 5 January 2020,

Revision received: 11 May 2020.

Accepted for publication: 25 May 2020.

This work is licensed under a Creative Commons AttributionNonCommercial 4.0 International License (CC BY-NC 4.0).

CC Copyright: the Author(s), 2020

Licensee PAGEPress, Italy

Health Psychology Research 2020; 8:8796

doi:10.4081/hpr.2020.8796
Attachment Scale (RAAS) and Quality of life questionnaire (SF36) were used as data gathering scale. The data were analyzed with SPSS ver. 19 using the Pearson correlation coefficient and linear regression. The participants' mean quality of life score was $74.2 \pm 16.7$. In attachment style, $48.7 \%$ of the participants had secure attachment, $26.0 \%$ avoidant attachment, and $25.0 \%$ ambivalent attachment. The results of this study indicated a significant direct correlation between the quality of life scores and secure attachment style ( $p$ value $<0.000)$. Also, there was a significant inverse correlation between the quality of life score and ambivalent attachment style ( $p$ value $<0.000)$. Attachment style predicted students' quality of life. Moreover, the role of Attachment style highlighted potential areas for intervention to improve medical student well-being and provide a foundation for longitudinal follow-up.

\section{Introduction}

Quality of life is one of the most basic structures in psychology (Szramka-Pawlak, Hornowska, Walkowiak, \& Żaba, 2014). The World Health Organization (WHO), in 1993, defined it as follows: "Quality of life is an individual's perception of their position in life in the context of the culture and value systems in which they live and in relation to their goals, expectations, standards, and concerns" (Fayers \& Machin, 2013). Today, quality of life is one of the main concerns of healthcare professionals, which is used as an central indicator for measuring health status in health research, evaluating different therapeutic approaches, and investigating long-term changes in individuals and the healthcare delivery system (Craig, Blumgart, \& Tran, 2009; Klassen, Miller, \& Fine, 2004).

Students are considered as one of the most important classes of the community, whose quality of life is of great importance (Paro et al., 2010). The students' quality of life is influenced by various psychological and social factors (Bodner \& Cohen-Fridel, 2010). University students face a drastic period in their education course, which may be related to more various problems than the other society members (Barron, 2007). Due to sudden separation from family and changes in their residence, students are more at risk of health issues (Rezaei Adaryani, 2007).

Medical students face multiple request, including potential liability, high expectations, on-call responsibilities, and competitive training (Thompson, Wrath, Trinder, \& Adams, 2018). Furthermore, daily encounters with suffering and death of patients, accumulation of debt, long hours studying large volumes of content, and working in cadaver labs have been identified par- 
ticularly stressful. As a result, compared to age-matched students, medical students report a decline in life satisfaction by graduation (Boeckers et al., 2010). Similar findings show that more than $50 \%$ of medical students report burnout based on self-report measures of emotional exhaustion, depersonalization, and a low sense of personal accomplishment (Dyrbye \& Shanafelt, 2016). These findings suggest that medical education is a highly demanding teaching environment where students' vulnerabilities may be tested. Therefore, to guide the development of effective evidence-based preventive measures and interventions, a better understanding of the individual psychological factors is needed that can either predispose or protect medical students in the face of this high degree of stress.

Quality of life is affected by two kinds of social and individual factors. Attachment style to parents is an individual factor that has attracted the attention of many researchers (Woodward et al., 2013).

The results of a study by Moghadam and colleagues indicate a relationship between attachment style and the sense of control and domination over the environment (Moghadam, Rezaei, Ghaderi, \& Rostamian, 2016). Zilcha-Mano also find that those with insecure attachment styles limit their interpersonal relations due to their inability to dominate the environment and establish positive relations (Zilcha-Mano, 2019). Noftle and Shaver (2006) and Tatnell, Hasking, Newman, Taffe, and Martin (2017) state that people with a secure attachment style use emotional regulation strategies that minimize stress and activate positive emotions, while those with insecure attachment styles use emotional regulation strategies that emphasize negative emotions. According to the above studies, there is a relationship between attachment style and the moods of students throughout the day. Thus, the attachment style plays a vital role in shaping their relations in society and thereby influencing their quality of life.

Medical students' attachment styles play an important role in communicating effectively with the patient (Kaya, 2012). Awareness of attachment styles and communication needs help caregivers professionals understand the role that attachment styles play in patient-caring team communications (Basharpoor, Narimani, \& Atadokht, 2015). Given the key role of medical students in maintaining and promoting community health in the future, it is necessary to pay attention to their quality of life and identify factors affecting it; they can provide services to patients in a desirable way if they have a good spirituality, psychology, and mental status.

\section{Materials and Methods}

\section{Study design and settings}

This cross-sectional correlational study was performed on students in Iranshahr University of medical science in a southeast province of Iran, in 2018.

\section{Participants and sampling}

The sample size determined a pilot study. According to formula , at a $95 \%$ confidence level and $80 \%$ power, the sample size estimated 120 students. Given the probability of participant dropout, the final sample size was considered to be 150 .

Inclusion criteria were as follows: having a desire to participate in the study and not taking drugs affecting the mood. The research subjects were selected randomly according to the list given by the Education Unit.

\section{Instruments and data collection}

The instruments used in the present study included demographic information form, quality of life questionnaire (SF-36), and Revised Adult Attachment Scale (RAAS).

Quality of life questionnaire (SF-36): SF-36 is one of the main tools used for assessing the quality of life, which can also be used by healthy people. This questionnaire includes 36 questions and 8 dimensions: limitations of activities (10 questions), physical health problems (4 questions), emotional health problems (3 questions), pain (2 questions), social activities (2 questions), mental health (5 questions), energy and emotions (4 questions), and general health (6 questions). The lowest total score for this questionnaire is zero, and the highest one is 124 . The higher the score, the higher the quality of life. The validity and reliability of the Persian version of this questionnaire have been confirmed at the Iranian Institute for Health Sciences Research, Kashan, Iran. In this study, the convergent validity test was used to confirm the validity of this questionnaire, and all estimated correlation coefficients were greater than the recommended value $(0.4)$ in the range from 0.88 to 0.95 (16). Moreover, to verify the reliability, the Cronbach's alpha coefficient was estimated, which was obtained in the range from 0.77 to 0.90 (Motamed, Ayatollahi, Zare, \& Sadeghi Hassanabadi, 2005).

The Revised Adult Attachment Scale (RAAS) is a self-report scale designed by Collins and Reid that asks participants to assess their relationship-building skills and describe how their attachment is shaped in a close relationship. It includes 18 questions designed based on secure, avoidant, and ambivalent attachments. Each statement is scored based on a 5 -point Likert scale $(0=$ completely disagree to $5=$ completely agree) (Craig et al., 2009). Those statements with higher scores are considered as an individual's attachment style. Collins and Reid (1990, from the chaste, 1380) report Cronbach's alpha coefficient of subscales secure, avoidant, and ambivalent attachment as $0.81,0.78$, and 0.85 , respectively (Mohammadimehr \& Karimi, 2017). In Iran, the validity and reliability of the Persian version of this tool have been measured by Pakdaman et al. In this study, its construct validity was measured by divergent validity ranging from -0.331 to 0.224 . Its reliability was assessed by the test-retest method; the coefficient of reliability was $0.73,0.68$, and 0.74 for the safe, avoidant, and ambivalent subscales, respectively (Shahla, 2004).

\section{Ethical considerations}

This study was conducted after being approved by the Ethics Committee of Iranshahr University of Medical Sciences (13-923).

\section{Statistical analysis}

Data were analyzed using SPSS 19 software. Pearson correlation test and linear regression test were used to examine the relationship between quality of life and attachment style, one-way ANOVA for the relationship between personal characteristics and education variables with quality of life and attachment styles, and Chi-square test for the relationship between qualitative variables.

$$
n=\frac{Z 1-\frac{\alpha^{2}}{2} s^{2}}{d^{2}}
$$




\section{Results}

The average age of participants was 20.4 years old, and they were in the $18-26$ age group. $50.0 \%$ of them were male. About $33.0 \%$ of them were nursing students, $23 \%$ midwifery students, $23 \%$ medical emergency students, and $21 \%$ operating room nursing students (Table 1).

In terms of attachment style, $48.7 \%$ of participants had a secure attachment style, $26 \%$ avoidant attachment style, and $25.3 \%$ ambivalent attachment style (Table 2). There was no significant difference between students in different fields and semesters in terms of attachment style. Moreover, there was no significant correlation between parents' education, birth rank, and marital status with attachment style ( $\mathrm{p}$ value $>0.05$ ).

The average score of quality of life of the whole participants was $74.2 \pm 16.7$. The results of the Pearson test showed a significant direct correlation between the average quality of life score and secure attachment style. In addition, there was also a significant inverse correlation between the quality of life score and ambivalent attachment style (Table 3).

Besides, the results of linear regression analysis, performed to predict the quality of life variable with secure, avoidant, and ambivalent attachment styles, showed that attachment styles explain $13.8 \%$ of the changes in quality of life variable $(\mathrm{T}=3.687$, $\mathrm{p}<0.000$ ). According to the results of this test, secure and ambivalent attachment styles were a predictor variable for quality of life. They have a significant predictive effect on the quality of life;
Table 1. Demographic characteristics of the students.

\begin{tabular}{llc} 
Characteristics & & Frequency (\%) \\
Gender & Female & $75(50.0)$ \\
& Male & $75(50.5)$ \\
Marital status & Married & $19(13.3)$ \\
& Single & $131(86.7)$ \\
\hline Study field & Nursing & $50(33.0)$ \\
& Midwifery & $35(23.0)$ \\
& Medical emergency & $35(23.0)$ \\
Parent's aliveness & Operating room nursing & $30(21.0)$ \\
& Only father & $1(0.7)$ \\
& Only mother & $5(3.2)$ \\
\hline Age (mean \pm SD) & Both & $144(95.1)$ \\
Grade point average & $20.4 \pm 2.4$ & \\
(mean \pm SD) & $16.5 \pm 1.5$ & \\
\hline Birth Rank & & \\
\hline
\end{tabular}

Table 2. Participants' average scores of attachment styles.

\begin{tabular}{lcc} 
Variable & mean \pm SD & N \\
Secure & $13.5 \pm 3.0$ & 150 \\
Avoidant & $12.8 \pm 3.5$ & 150 \\
\hline Ambivalent & $11.0 \pm 5.1$ & 150 \\
\hline
\end{tabular}

Table 3. Correlations between students' quality of life and attachment styles.

\begin{tabular}{|c|c|c|c|c|}
\hline Variable & Mean \pm sd & $\begin{array}{c}\text { Secure } \\
\text { Correlation p value }\end{array}$ & $\begin{array}{c}\text { Avoidant } \\
\text { Correlation p value }\end{array}$ & $\begin{array}{c}\text { Ambivalent } \\
\text { Correlation p value }\end{array}$ \\
\hline Total quality of life & $74.2 \pm 16.7$ & $\begin{array}{l}0.611 \\
0.000\end{array}$ & $\begin{array}{c}-0.064 \\
0.437\end{array}$ & $\begin{array}{c}-0.236 \\
0.457\end{array}$ \\
\hline Mental health & $11.6 \pm 3.9$ & $\begin{array}{l}0.505 \\
0.000\end{array}$ & $\begin{array}{c}-0.084 \\
0.310\end{array}$ & $\begin{array}{c}-0.296 \\
0.000\end{array}$ \\
\hline General health & $11.3 \pm 4.0$ & $\begin{array}{l}0.555 \\
0.000\end{array}$ & $\begin{array}{l}-0.162 \\
0.045\end{array}$ & $\begin{array}{c}-0.141 \\
0.085\end{array}$ \\
\hline Emotional health problems & $8.0 \pm 3.4$ & $\begin{array}{l}0.287 \\
0.000\end{array}$ & $\begin{array}{c}-0.028 \\
0.732\end{array}$ & $\begin{array}{c}-0.182 \\
0.028\end{array}$ \\
\hline Physical health problems & $11.5 \pm 4.1$ & $\begin{array}{l}0.345 \\
0.000\end{array}$ & $\begin{array}{l}-0.154 \\
-0.061\end{array}$ & $\begin{array}{l}-0.007 \\
-0.933\end{array}$ \\
\hline Social activities & $4.9 \pm 1.8$ & $\begin{array}{l}0.576 \\
0.000\end{array}$ & $\begin{array}{c}-0.236 \\
0.004\end{array}$ & $\begin{array}{c}-0.263 \\
0.001\end{array}$ \\
\hline Limitations of activities & $15.7 \pm 4.6$ & $\begin{array}{l}0.308 \\
0.000\end{array}$ & $\begin{array}{c}-0.034 \\
0.679\end{array}$ & $\begin{array}{c}-0.085 \\
0.303\end{array}$ \\
\hline Energy and emotions & $8.8 \pm 3.4$ & $\begin{array}{l}0.346 \\
0.000\end{array}$ & $\begin{array}{c}-0.071 \\
0.390\end{array}$ & $\begin{array}{c}-0.177 \\
0.031\end{array}$ \\
\hline Pain & $6.1 \pm 1.7$ & $\begin{array}{l}0.073 \\
0.372\end{array}$ & $\begin{array}{c}-0.050 \\
0.545\end{array}$ & $\begin{array}{c}-0.056 \\
0.496\end{array}$ \\
\hline
\end{tabular}

Table 4. Results of enter linear regression test performed to predict quality of life through attachment style.

\begin{tabular}{lccccc} 
Predictor variable & B & SE & Beta & T & P \\
Constant & 6.087 & 1.651 & - & 3.687 & 0.000 \\
Secure attachment & 0.376 & 0.091 & 0.330 & -130 & 0.000 \\
\hline Avoidant attachment & -0.073 & 0.082 & -0.073 & -0.885 & -2.385 \\
Ambivalent attachment & -0.132 & 0.055 & -0.190 & & 0.018 \\
\hline
\end{tabular}


however, the predictive effect of avoidant attachment style was not significant. The quality of life score changed by 1 score when the score of secure and ambivalent attachment styles changed by 0.33 and -0.19 score, respectively (Table 4).

\section{Discussion}

The results of the present study showed a significant relationship between students' attachment styles and their quality of life, and those with a secure attachment style had a higher quality of life score. Also, the ambivalent attachment style negatively influenced the quality of life. Moreover, the results showed that the secure attachment style had a predictive role in determining the students' quality of life. This result was consistent with the studies by Noftle and Shaver (2006), Brumbaugh and Fraley (2006), and MarsaSambola et al. (2017).

A secure attachment process results are in the sense of security in a person, while the results of insecure attachments are fear. In this regard, Zeidner, Matthews, and Roberts (2012) state that the consequence of insecure attachment style is anxiety and depression, while the psychological consequence of the secure attachment style is mental relaxation and thereby higher quality of life.

Hart and Howard (2016) believe that attachment styles influence the quality of life by creating a bias on encoding, reminding, and influencing processes of explanation of unpleasant conditions; thus, the secure attachment style has a positive bias and enhances the quality of life, and insecure style has a negative bias and reduces the quality of life.

Noftle \& Shaver (2006) argue that secure attachment style is a secure source for dealing with stress, while insecure attachment style does not provide such a source, and against stresses, they leave a person alone and helpless and even eliminate an individual's mild coping strategies. In other words, the secure attachment style is one of the richest intrapersonal sources and empowers an individual against stresses and unpleasant effects, and lack of it makes a person vulnerable to crisis. According to Karreman and Vingerhoets (2012), a secure attachment style is associated with a sense of well-being, which positively affects the quality of life.

Concerning the relationship between attachment style and quality of life scales, the results of the present study revealed direct relationships between secure attachment style and quality of life scales, including mental health, general health, vitality, social functioning, role limitations due to emotional problems, role limitations due to physical problems and functioning; increasing it, results in an increase in the scores of these scales.

The results of studies by Zheng, Zhu, Zhao, and Zhang (2015), Kor, Mikulincer, \& Pirutinsky (2012), and West and Sheldon (1998) also showed that secure attachment style enhances individuals' physical and mental health.

However, two studies on US medical students suggest lower rates of insecurity and higher rates of secure attachment than our study. For instance, when exploring the relationship between attachment and specialty choice in US medical students, two studies find that almost $60 \%$ of medical students (56\% and 59\%) have a secure attachment (Ciechanowski, Russo, Katon, \& Walker, 2004; Ciechanowski, Worley, Russo, \& Katon, 2006). Even though both studies find the same level of attachment security, the attachment distribution cannot be explained by the variation in gender distribution (one study has significantly more male subjects, while the other has significantly more females). Interestingly, both of these studies identify significantly higher percentages of married or living as married students (57\% and 31\%) compared to our sample $(13 \%)$. This might suggest that medical students in committed relationships might benefit from protective support and intimacy, which are likely to alleviate insecure attachment. These findings are consistent with recent research, showing the healing role played by positive intimacy-promoting relationships on attachment insecurity.

The pre-existing insecure attachment might impact the ability to cope and maintain a balanced life when face school pressures that, in turn, can impact the perception of the stress level.

This is also in line with previous literature, suggesting a higher level of stress reported by individuals with preoccupied and fearful attachment.

Conversely, the high paced medical training can affect the perception and expression of attachment security in close relationships, given the demands of energy and time commitment; this is likely to impact personal life and, therefore, close relationships. These reciprocal influences fit with previous understanding of attachment as having both trait and state components. For instance, while attachment has been overall regarded as moderately stable through life, the impact of various life situations on attachment has also been acknowledged. Moreover, our data collection is timed at the beginning of the academic year, which might also fail in capturing the full level of stress associated with prolonged exposure to school stressors and exam periods.

Assessing obvious incidents and events during perception of a possible or actual threat results in the activation of attachment system; in people with a secure attachment, this cycle involves the reduction of unpleasant stress, an increase of individual adaptability, and, consequently, improvement of quality of life (AddingtonHall \& Kalra, 2001).

\section{Conclusions}

Medical students face unique training and psychological challenges, requiring better understanding and support. Attachment style appears to play key roles in the quality of life. Secure attachment style positively predicts quality of life and enhances it through positive cognitive-emotional processes, while insecure attachment style reduces the quality of life due to the negative cognitive-emotional processes. Also, people with a secure attachment style have fewer interpersonal problems than those with an insecure attachment style. People with insecure attachment styles face more emotional and mental problems; the more disability people feel, the lower their quality of life.

Despite some of the intrinsic stressors of training in medical schools, understanding these individual vulnerabilities and protective factors might aid in designing interventions that subtilize the student's resilience, alleviate attachment insecurity, and promote well-being. As medical schools continue to implement supports and programming, empiric validation is necessary, where attachment style may prove valuable subjects for further study.

\section{Refrences}

Addington-Hall, J., \& Kalra, L. (2001). Who should measure quality of life? Bmj, 322(7299), 1417-1420.

Barron, L.W. (2007). Effect of religious coping skills training with group cognitive-behavioral therapy for treatment of depression: ProQuest. 
Basharpoor, S., Narimani, M., \& Atadokht, A. (2015). The role of attachment styles in the prediction of posttraumatic stress disorder in emergency nurses. Iran J Crit Care Nurs, 7(4), 237244.

Bodner, E., \& Cohen-Fridel, S. (2010). Relations between attachment styles, ageism and quality of life in late life. International Psychogeriatrics, 22(8), 1353-1361.

Boeckers, A., Brinkmann, A., Jerg-Bretzke, L., Lamp, C., Traue, H.C., \& Boeckers, T.M. (2010). How can we deal with mental distress in the dissection room?-An evaluation of the need for psychological support. Annals of Anatomy-Anatomischer Anzeiger, 192(6), 366-372.

Brumbaugh, C.C., \& Fraley, R.C. (2006). Transference and attachment: How do attachment patterns get carried forward from one relationship to the next? Personality and Social Psychology Bulletin, 32(4), 552-560.

Ciechanowski, P.S., Russo, J.E., Katon, W.J., \& Walker, E.A. (2004). Attachment theory in health care: the influence of relationship style on medical students' specialty choice. Medical education, 38(3), 262-270.

Ciechanowski, P.S., Worley, L.L., Russo, J.E., \& Katon, W.J. (2006). Using relationship styles based on attachment theory to improve understanding of specialty choice in medicine. $B M C$ medical education, 6(1), 3.

Craig, A., Blumgart, E., \& Tran, Y. (2009). The impact of stuttering on the quality of life in adults who stutter. Journal of fluency disorders, 34(2), 61-71.

Dyrbye, L., \& Shanafelt, T. (2016). A narrative review on burnout experienced by medical students and residents. Medical education, 50(1), 132-149.

Fayers, P.M., \& Machin, D. (2013). Quality of life: the assessment, analysis and interpretation of patient-reported outcomes: John Wiley \& Sons.

Hart, J., \& Howard, R.M. (2016). I want her to want me: Sexual misperception as a function of heterosexual men's romantic attachment style. Personality and Individual differences, 92, 97-103.

Karreman, A., \& Vingerhoets, A.J. (2012). Attachment and wellbeing: The mediating role of emotion regulation and resilience. Personality and Individual differences, 53(7), 821-826.

Kaya, N. (2012). Effect of attachment styles of individuals discharged from an intensive care unit on intensive care experience. Journal of critical care, 27(1), 103. e107-103. e114.

Klassen, A.F., Miller, A., \& Fine, S. (2004). Health-related quality of life in children and adolescents who have a diagnosis of attention-deficit/hyperactivity disorder. Pediatrics, 114(5), e541-e547.

Kor, A., Mikulincer, M., \& Pirutinsky, S. (2012). Family functioning among returnees to Orthodox Judaism in Israel. Journal of Family Psychology, 26(1), 149.

Marsa-Sambola, F., Williams, J., Muldoon, J., Lawrence, A., Connor, M., \& Currie, C. (2017). Quality of life and adolescents' communication with their significant others (mother, father, and best friend): The mediating effect of attachment to pets. Attachment \& human development, 19(3), 278-297.
Moghadam, M., Rezaei, F., Ghaderi, E., \& Rostamian, N. (2016). Relationship between attachment styles and happiness in medical students. Journal of family medicine and primary care, 5(3), 593.

Mohammadimehr, Z., \& Karimi, B.A. (2017). The relationship between emotional intelligence, attachment styles and optimism with martials satisfaction. Iranian Journal of Educational Sociology, 1(2), 50-58.

Motamed, N., Ayatollahi, A., Zare, N., \& Sadeghi Hassanabadi, A. (2005). Validity and reliability of the Persian translation of the SF-36 version 2 questionnaire.

Noftle, E. E., \& Shaver, P. R. (2006). Attachment dimensions and the big five personality traits: Associations and comparative ability to predict relationship quality. Journal of research in personality, 40(2), 179-208.

Paro, H. B., Morales, N. M., Silva, C. H., Rezende, C. H., Pinto, R. M., Morales, R. R., Mendoça, T.M.S. Prado, M. M. (2010). Health $\square$ related quality of life of medical students. Medical education, 44(3), 227-235.

Rezaei Adaryani, M. (2007). Comparison of depression, anxiety, stress and quality of life for Male and female students living in Tarbeyat Modares student dormitories. Pajoheshe Parastari, 2(4), 31-38.

Shahla, P. (2004). The relationship between attachment and community seeking in adolescence. JPS???, 3(9), 25-47.

Szramka-Pawlak, B., Hornowska, E., Walkowiak, H., \& Żaba, R. (2014). Hope as a psychological factor affecting quality of life in patients with psoriasis. Applied research in quality of life, 9(2), 273-283.

Tatnell, R., Hasking, P., Newman, L., Taffe, J., \& Martin, G. (2017). Attachment, emotion regulation, childhood abuse and assault: examining predictors of NSSI among adolescents. Archives of suicide research, 21(4), 610-620.

Thompson, G., Wrath, A., Trinder, K., \& Adams, G. C. (2018). The roles of attachment and resilience in perceived stress in medical students. Canadian medical education journal, 9(4), e69.

West, M., \& Sheldon, A. E. (1988). Classification of pathological attachment patterns in adults. Journal of Personality Disorders, 2(2), 153-159.

Woodward, M. J., Patton, S. C., Olsen, S. A., Jones, J. M., Reich, C. M., Blackwell, N., \& Beck, J. G. (2013). How do attachment style and social support contribute to women's psychopathology following intimate partner violence? Examining clinician ratings versus self-report. Journal of anxiety disorders, 27(3), 312-320.

Zeidner, M., Matthews, G., \& Roberts, R. D. (2012). What we know about emotional intelligence: How it affects learning, work, relationships, and our mental health: MIT press.

Zheng, X., Zhu, W., Zhao, H., \& Zhang, C. (2015). Employee wellbeing in organizations: Theoretical model, scale development, and cross-cultural validation. Journal of Organizational Behavior, 36(5), 621-644.

Zilcha-Mano, S. (2019). Major developments in methods addressing for whom psychotherapy may work and why. Psychotherapy Research, 29(6), 693-708. 